\title{
Do Construction Costs Reflect the True Information in the Real Estate Markets?
}

\author{
Ruihu Kuang \\ Australian School of Business, University of New South Wales, Sydney NSW 2052 Australia \\ r.kuang@student.unsw.edu.au,wrx323@163.com
}

\begin{abstract}
Many academics criticized municipal governments and state-owned enterprises (SOEs) promote land prices to increase. The criticism is based on the assumption that land prices reflect the true information in the land transactions. However, municipal governments and SOEs might be misled by information hidden in land prices. Land prices are a part of construction costs. My contribution was to find out whether construction costs provide misleading information. The methodologies were based on the fixed- effects model and the dynamic model considering cross-section dependence, using the fixed- effects regression and the augmented mean group estimation. By studying the relationships between construction costs and factors affecting construction costs, I found that construction costs do not response to any change in different variables, which are average incomes and real estate investments except the bubbles. Therefore, construction costs deliver misleading information, which violates the assumption, many academic believed.
\end{abstract}

Keywords-construction costs; misleading information; the fixed- effects model; the dynamic model considering crosssection dependence.

\section{INTRODUCTION}

A better understanding cost of real estate is an important task of real estate management. The construction costs have received relatively little attention in the literature on housing bubbles. Construction costs here are a unit price of a completed house in cities, including land prices, costs of materials, labours and transportation etc. However, many academics focus on research of land prices, believing that rapid growth in land prices in Chinese cities led to increasing house prices. Shuanglin Lin et al. $(2008)^{[1]}$ showed that governments got great benefits from selling urban lands, which pushed up land prices. Lin Liang Peng \& Thomas G. Thibodeau $(2012)^{[2]}$ also indicated that the residential land markets were less efficient after municipal governments kept the land supplies under control. Similarly, Hongyan Dua et al. $(2011)^{[3]}$ indicated that land markets became less efficient after analysing long-run and short-run equilibriums between Chinese urban housing and land markets. These papers did not provide enough evidence whether governments' behaviours led to land markets' inefficiency. They also did not indicate why governments should be blamed for skyrocketing land prices when the land markets became more marketization after land reforms in 2004.
The academics above mainly worked on impact of governments' behaviours on land markets, while some academics studied influence of state-owned enterprises (SOEs) on the land markets. Jing $\mathrm{Wu}$ et al. (2012) ${ }^{[4]}$ claimed SOEs paid about $30 \%$ more than other bidders for an otherwise equivalent land parcel. Weidong $\mathrm{Qu}$ et al. $(2012)^{[5]}$ also came up with the similar conclusion that $\mathrm{SOE}$ in the land markets tended to pay more than counterparts. They pointed out SOEs were low-risk borrowers and could be easier to finance from commercial banks than most private companies. However, these papers did not explain why SOEs were willing to pay more in the land transactions, even though they had stronger financial ability.

However, it is possible that aggressive purchasing lands of SOEs comes from misleading land prices. When SOEs realized that they had to pay much more to make sure they gained the land, they could be willing to pay more. But the prices they pay might contain bubbles, which were out of their recognitions. SOEs might be misled by information reflected in land prices. The governments' behaviours also might become irrational when land prices include misleading information. Limited data can be found in Chinese cities. Thus, the paper contributes to provide empirical evidence on whether construction costs deliver misleading information.

\section{VARIABLES USED IN ANALYSES}

Variables make up construction costs, average incomes, and real estate investments in Chinese cities in different years. Construction costs reflect a unit price of a completed house in cities, measured in yuan per square meter. Average incomes are measured in yuan in a year in cities, while real estate investments denote amount of real estate investments in cities, measured in 10000 yuan.

\section{METHOD FRAMEWORK}

My analyses are based on two steps. First, I investigate whether there are significant relationships between construction costs and factors of affecting construction costs, including average incomes, and real estate investments. I also further explain the estimation results and test whether the relationships are reliable. In the step, I attempt to discover relationships between construction costs and factors of affecting construction costs, no matter whether bubbles are contained in construction costs. In the second step, I try to examine relationships between construction costs and factors of affecting construction costs when an evolving 
unobservable variable, considered as bubbles, is built to be separated from construction costs. By comparing estimation results in the first step with that in the second step, I can determine whether construction costs deliver misleading information.

In the first step, I use the fixed- effect model to find out the relationships. The model is specified as follows.

$\log C_{i t}=\alpha_{i}+\beta \times \log X_{i t}+\varepsilon_{i t}$

Where $i$ and $t$ represent different cities and different years respectively, $C_{i t}$ is natural $\log$ of construction costs in different cities in different years. $X_{\text {it }}$ is a set of natural log of variables including average incomes, and real estate investments in different cities in different years. $\alpha_{i}$ indicates unobservable time-invariant city effects. $\varepsilon_{\text {it }}$ denotes the error terms, following the distribution with zero mean and variance $\sigma^{2} . \beta$ are coefficients of $X_{i t}$ and reflect relationships between $\log P_{i t}$ and $\log X_{\text {it }}$.

The fixed-effects regression is employed to estimate the model. When construction costs contain bubbles, the estimation results from the model must be bias even though the results can pass consistent tests, such as $t$ test or $F$ test. To examine whether the results are bias, I conduct pesaran test (Pesaran, M.H., 2004 ${ }^{[6]}$ ) to test the cross-sectional dependence in estimation results. Pesaran test is one of cross-sectional tests. The test is better than other tests in two ways. One is that it is fit for testing panel data models with small $\mathrm{T}$ and large $\mathrm{N}$. The other one is that it can test balanced and unbalanced panels.

In the second step, dynamic empirical models for analysing construction costs which include evolving bubbles are set up as follow.

$$
\begin{array}{ll}
\log C_{i t}=\lambda_{i t}+\eta \times \log X_{i t}+\gamma_{i t} & (2) \\
\gamma_{i t}=C \times \mu_{t}+\varepsilon_{i t} & (3) \\
\mu_{t}=m \times \mu_{t-1}+\zeta_{i t} & (4)
\end{array}
$$

In this setup, cross-section dependence is captured by an unobservable common factor $\mu_{t} . \lambda_{i t}$ is a constant. $\eta, C$ and $m$ are coefficients. The distributions of error components of $\varepsilon_{i t}$ and $\zeta_{i t}$ follow zero mean and variance $\sigma^{2} \cdot \log C_{i t}$ and $\log X_{i t}$ have the same definitions as in the former model. The methodology to estimate the model is augmented mean group estimator (AMG), introduced by Eberhardt and Teal $(2010)^{[7]}$. The advantage of the method is that it is fit for analysing relationships between non-stationary variables. Besides, the method considers a dynamic unobservable variable into estimation, which represents bubbles in my case. Some literature, such as Eddie Chi Man Hui, et al. (2013) ${ }^{[8]}$ employs the dynamic unobservable variable as house bubbles as well.

The AMG follows two procedures.

$$
\begin{aligned}
& \Delta \log C_{i t}=\eta \times \Delta \log X_{i t}+\sum_{2}^{T} \mu_{t} \times \Delta K_{t}+\varepsilon_{i t} \\
& \log C_{i t}=\lambda_{i t}+\eta \times \Delta \log X_{i t}+\widetilde{\mu}_{t} \times K_{i}+\varepsilon_{i t}
\end{aligned}
$$

Where, $\mathrm{C}_{\mathrm{it}}, \mathrm{X}_{\mathrm{it}}, \lambda_{i t}$ and $\eta$ are the same as in the former model. The term $\sum_{2}^{T} \mu_{t} \times \Delta K_{t}$ is used to estimate the dynamic evolving bubbles.

The first stage is implemented by pooled OLS regression of the first-differences model in (5). The estimated coefficients augmented with $\mathrm{T}-1$ differenced year dummies $\mathrm{Kt}$, labelled as, $\tilde{\mu}_{t}$ indicate evolution of an unobservable variable over time. It is referred to as the 'common dynamic process'. In the second stage (6), the 'common dynamic process' is imposed on each group member. $K_{i}$ represents the implicit factor loading on the common evolving unobservable variable. After subtracting $\tilde{\mu}_{t} \times K_{i}$ from $\log C_{i t}$, long term real relationships between $\log C_{i t}$ and $\log X_{i t}$ can be confirmed.

\section{RESULTS OF COMPUTATION AND ANALYSIS}

The panel data in my analyses come from China Statistical Yearbook. They are annually and include 31 provinces from 1996 to 2012, which focus on Chinese cities.

\section{A. Results of the fixed-effects regression}

TABLE I. RESULTS OF THE FIXED- EFFECTS REGRESSION

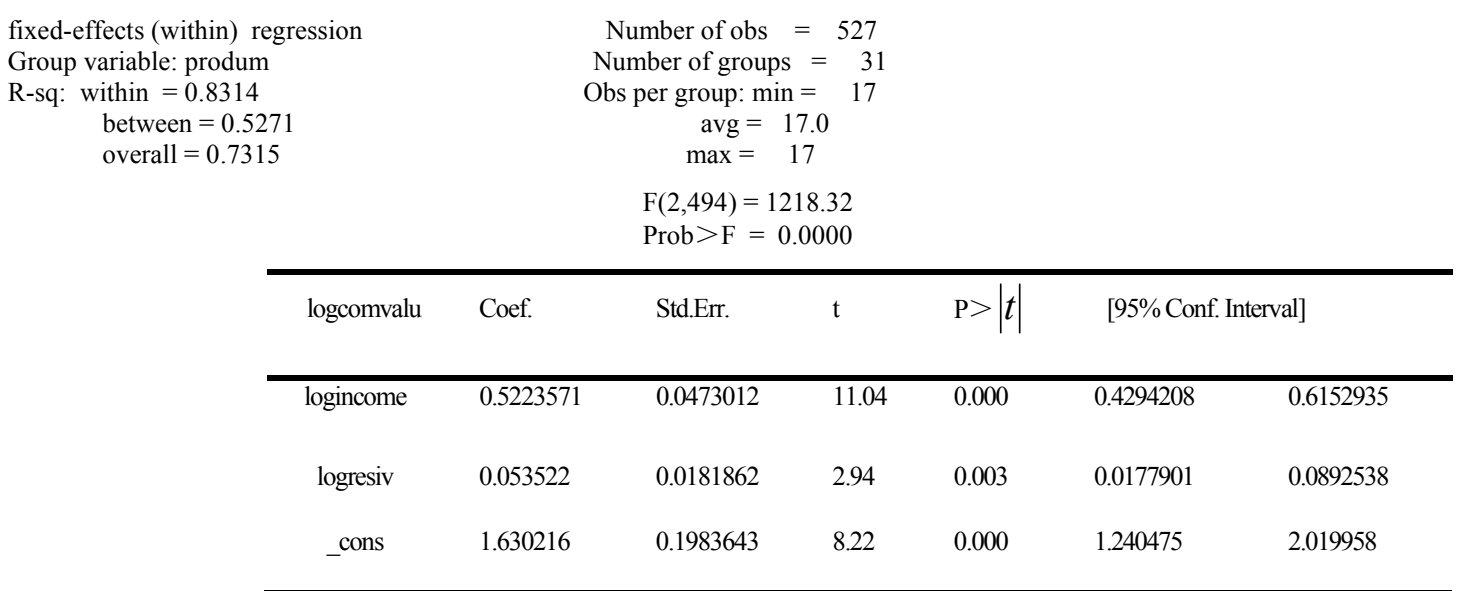

F test that all $\mathrm{u}_{-} \mathrm{i}=0: \mathrm{F}(30,494)=17.52 \quad$ Prob $>\mathrm{F}=0.0000$

Note: logcomvalue, logincome, and logresiv denote natural logs of construction costs, average incomes, and real estate investments respectively. 
The table states that coefficients are joint significant as $\mathrm{p}$ value for $\mathrm{F}$ test statistics is 0 . All coefficients are significant in $5 \%$ confidence level. The coefficients represent how responsive construction costs are to a change in different variables, which are average incomes and real estate investments. For instance, the coefficient of logincome indicates that when average incomes increase $1 \%$, construction costs increase by $0.5 \%$. However, it is mentioned as before, the analyses only illustrate the relationships between construction costs and factors of affecting construction costs when bubbles are hidden in construction costs. To find out the limitation of the model, a further test proceeds.

\section{B. A result of pesaran test}

Pesaran's test of cross sectional independence $=31.965$, $\operatorname{Pr}=0.0000$

The result demonstrates there is potential bias in the former model as probability of accepting the null hypothesis that cross sections are independent is 0 . The limitation of the model is derived from people's perception as people only observe construction costs but do not realize there are bubbles in the costs.

\section{Results of the AMG estimation}

TABLE II. RESULTS OF THE AMG ESTIMATION

xtmg logcomvalu logincome logresiv, aug

Augmented Mean Group estimator (Bond \& Eberhardt, 2009; Eberhardt \& Teal, 2010)

Common dynamic process included as additional regressor

All coefficients present represent averages across grops (produm)

Coefficient averages computed as unweighted means

$\begin{array}{lll}\text { Mean Group type estimation } & \text { Number of obs } & =527\end{array}$

Group variable: produm $\quad$ Number of groups $=31$

Obs per group: $\min =17$

avg $=17.0$

$\max =17$

Wald chi2 (2) $=5.48$

Prob $>$ chi2 $=0.0644$

\begin{tabular}{|c|c|c|c|c|c|c|}
\hline logcomvalu & Coef. & Std. Err. & $\mathrm{z}$ & $\mathrm{P}>|z|$ & \multicolumn{2}{|c|}{ [ $95 \%$ conf. Interval ] } \\
\hline logincome & -0.0621975 & 0.1172139 & -0.53 & 0.596 & -0.2919326 & 0.1675375 \\
\hline logresiv & 0.0657079 & 0.0352366 & 1.86 & 0.062 & -0.0033545 & 0.1347703 \\
\hline 00000R_c & 1.027771 & 0.1018685 & 10.09 & 0.000 & 0.8281124 & 1.22743 \\
\hline cons & 6.47611 & 0.7117428 & 9.10 & 0.000 & 5.08112 & 7.8711 \\
\hline
\end{tabular}

Root Mean Squared Error (sigma): 0.0833

Variable_00000R_crefers to the common dynamic process.

Note : logcomvalu, logincome and logresiv and have the same meanings in Table 1._00000R_c reflects 'common dynamic process'.

The table shows joint significant for all coefficients in $10 \%$ confidence level as 'Prob $>$ chi 2 ' is $6.44 \%$. All coefficients of the variables are insignificant except the constant and a common dynamic process, as $\mathrm{p}$ values for these coefficients are large than 5\%. These results confirm that bubbles, which are treated as the common dynamic process, appear in the construction costs. However, the results also verify that when house bubbles are separated from the construction costs, all significant relationships between construction costs and other variables in the fixed-effects regression do not exist in the estimation. In other words, construction costs do not response to any change in different variables, which are average incomes and real estate investments except the bubbles. These analyses can demonstrate that construction costs in cities have less flexible or resilient as expected as they contain bubbles. Therefore, governments and institutions are easily misled by information hidden in construction costs.

\section{CONCLUSIONS}

1) Two models were used to analyse the relationships between construction costs and factors affecting construction costs, which can examine whether construction costs reflect the true information.

2) The estimation results from the first model reflect that there are significant relationships between construction costs and factors, regardless of house bubbles hidden in the house prices. This reflects double limitations: one is for the model and another is for people's perception of real estate markets in cities.

3) The estimation results from the second model indicate that there are no significant relationships between the construction costs and factors when the bubbles are deleted from construction costs. This implies that the real estate markets in cities are overheated and have their limitations to a considerable extent when housing bubbles are concealed in the construction costs.

What has been discussed above illustrates that governments and institutions (such as SOEs) are easily misguided by the false information of housing bubbles hidden in the construction costs.

\section{REFERENCES}

[1] Shuanglin Lin. Forced Savings, Social Safety Net, and Family Support: A New Old-Age Security System for China. Chinese Economy, 41 (6), pp.10-44, 2008. 
[2] Liang Peng \& Thomas G. Thibodeau, Government Interference and the Efficiency of the Land Market in China. Journal of Real Estate Finance Economic, 45, pp.919-938, 2012.

[3] Hongyan Dua, Yongkai Maa, Yunbi Anb., The impact of land policy on the relation between housing and land prices: Evidence from China. The Quarterly Review of Economics and Finance, 51, pp.19-27, 2011.

[4] Jing $\mathrm{Wu}$, Joseph Gyourko and Yongheng Deng, Evaluating conditions in major Chinese housing markets. Regional Science and Urban Economics, 42 (3), pp. 531-543, 2012.
[5] Weidong Qu, Xiaolong Liu. Assessing the Performance of Chinese Land Lease Auctions: Evidence from Beijing. Journal of Real Estate Research. 34 (3), pp.291-310,2012.

[6] Pesaran, M.H., General diagnostic tests for cross section dependence in panels, Cambridge Working Papers in Economics, 0435, University of Cambridge, 2004.

[7] Eberhardt M. \& Teal F., Productivity Analysis in Global Manufacturing Production, Oxford University, Department of Economics, Discussion Paper, 2010.

[8] Eddie Chi-Man Hui, Cong Liang, Ziyou Wang, Bo-Tong Song \& Qi $\mathrm{Gu}$, Real Estate Bubbles in China: A Tale of Two Cities. Construction Management and Economics, 30, pp.951-961, 2012. 